\title{
PH.D DEGREES AWARDED BETWEEN MARCH 1990 AND FEBRUARY 1991
}

Basa, K. The westerly trade of Southeast Asia from c.400 B.C. to c. A.D. 500 with special reference to glass beads.

Butler, A. Legumes in Antiquity: a micromorphological investigation of seeds of the Vicieae.

Ghaleb, B. An ethnoarchaeological study of Mabuiag Island, Torres Strait, Northem Australia.

Al-Ghazzi, A. A Comparative study of pottery from a site in the al-Kharj valley, Central Arabia.

Held, S. Early prehistoric island archaeology in Cyprus.

Holden, T.G. Taphonomic and methodological problems in reconstructing diet from ancient human gut and faecal remains.

Al-Mazroo, H. I. A stylistic and comparative study of unpublished preIslamic stone sculptures from Arabia

Reynolds, P. Late Roman pottery and settlement in the Vinalopó Valley (Alicante, Spain), A.D. 400-700.

Symmington, D. Kizzuwabna in the 2nd millenium B.C.

Trentin, M. Western Uruk period pottery assemblages and their Mesopotamian relatives.

Wettasinghe, S. C. A study of the chemical deterioration of paper using Fourier-transform infrared spectroscopy, and the stabilization and strengthening of mechanical wood papers.

\section{PH.D. ABSTRACTS}

Basa, K. The westerly trade of Southeast Asia from c.400 B.C. to C. A.D. 500 with special reference to glass beads

From the 1960's, archaeology in Southeast Asia has contributed to the development of a "Southeast Asian Personality" and, putting aside diffusionary and migration models has emphasized the intensive studies of small areas using a neo-evolutionary perspective. Now there is a need to study the region from a broader perspective, linking it to a wider area - hence this study on the external trade of Southeast Asia.

In this thesis, various approaches to trade and exchange in general, and Southeast Asia in particular, are discussed. The early westerly trade of Southeast Asia is analysed in terms of a world system perspective, which is different from the original scheme of Wallerstein. Firstly, the world system, as used in this thesis, will include not only politics and economics, but also, what Wallerstein ignored, ideology and cosmology. Secondly, instead of distinguishing the pre-eminence of politics and economics in a temporal scheme within the framework of "world empire" and "world economy" respectively, their role is determined in terms of spatial context. Thirdly, "core/centre" and "periphery" are used not as fixed and absolute concepts, but as relative to different spatial contexts. Fourthly, the periphery is not regarded as a passive recipient, but an active agent. Thus, the early external trade of Southeast Asia was part of a world system which extended from the Eastem Mediterranean to India on the west and to China on the north. 
In the studies of the westerly contacts of Southeast Asia, materials of the Late Prehistoric Period have been given less emphasis than those of the Early Historic Period, when archaeological, art historical, architectural and sculptural materials showing Indian or Chinese influences are abundantly available. Therefore in this study, primacy is given to materials of the Late Prehistoric Period, especially to glass beads from Ban Don Ta Phet, an Iron Age cemetery in Westcentral Thailand dated to the fourth century BC. It is argued that there was no manufacturing centre for glass beads in Southeast Asia until at least the early centuries of the Christian Era, and that glass beads were important items of import to Southeast Asia from India - which is shown by the morphological similarities and by chemical analyses of composition. This study of glass beads together with other archaeological finds, helps us to identify an early stage of culture contact between India and Southeast Asia.

\section{Butler, A. Legumes in Antiquity: a micromorphological} investigation of seeds of the Vicieae.

Early evidence for the importance of legumes in nutrition is limited by difficulties in the identification and interpretation of pulse remains from archaeological contexts.

This projects aims to seek in a detailed survey of legume seed micromorphology, criteria that can be used for the identification of species and, as evidence of cultivation. Assessment of the role of scanning electron microscopy (SEM) in archaeobotany is a supplementary aim. Study material has been selected from the leguminous tribe Vicieae, comprised of the four genera Vicia, Lathyrus, Lens and Pisum.

An atlas of seed micromorphology, illustrated by photographic plates, forms the basis for an identificatory key. A dataset, compiled from the results of both conventional light microscopy and SEM, and expressed numerically, has been subjected to multivariate analyses.

The results show that identifications of seeds of the Vicieae to species level using seed micromorphology are restricted to certain taxa, contrary to some published reports; but allocation of specimens to a higher taxonomic rank, using an array of criteria, is usually more realistic. Most useful characters are found in features in the hilar region. Clear evidence of cultivation has only been observed in the genus Pisum. Using SEM, similar data may be recorded equally in fresh seeds and fragments of charred archaeological specimens.

It is concluded that seeds of the Vicieae usually do not exhibit sufficient morphological differences for species identification. Evidence for cultivation may rather be sought in biochemical changes that facilitate control of the germination in seeds of cultigens. Future research into pulse biochemistry and agronomy is anticipated.

Ghaleb, B. An ethnoarchaeological study of Mabuiag Island, Torres Strait, Northern Australia.

In this thesis an ethnoarchaeological approach is applied to the study of past settlement and subsistence on the island of Mabuiag, one of the Western Torres Strait Islands situated midway between the continent of Australia and the continental island of New Guinea. This region of the world, 
and Mabuiag in particular, was selected for study on account of its methodological interest, i.e. the potential for interpreting archaeological remains found.

The present-day environmental and cultural setting of the Torres Strait region is discussed before the history of European contact in the area is reviewed. Information on the lifestyle of the Islanders and Cape York Aborigines contained in the earliest European records provides views of Islander life prior to sustained contact with Europeans. The nature and effects of the subsequent 30-40 years of European contact in the area are then considered in order to establish the validity of the analogical use of the latenineteenth century ethnographic accounts that relate most specifically to the archaeological research of this thesis: i.e. the Haddon Reports.

The appropriateness of the use of the Haddon Reports is demonstrated and aspects of the ethnography most relevant to the traditional patterns of settlement and subsistence on Mabuiag are discussed in relation to the objectives and results of the archaeological reconnaissance, survey and excavation carried out on Mabuiag Island. Interpretations of the archaeological data are presented both with and without consideration of the ethnographic information, and in conclusion the nature of the archaeological interpretations that can be developed when relevant ethnographic information is available is highlighted.

\section{Al-Ghazzi, A. A Comparative study of pottery from a site in the al-Kharj valley, Central Arabia}

The present thesis is devoted to a comparative study on a pottery corpus from site 207-30 (according to Saudi Arabian Dept. of Antiquities No.), located in the al-Kharj valley.

It contains 840 archaeological objects obtained through a fieldwork accompanied by excavations. For the study of these objects, the thesis is divided into six chapters.

Chapter 1 contains two parts aiming at presenting the site in a clear geographical setting. Chapter 2 contains two parts dealing with the occupation of the area in order to establish a periodization of the site. Chapter 3 deals with the actual fieldwork in six parts. Part 1 deals with directly relevant points to the site. Part 2 introduces the excavations and their stratigraphies. Part 3 deals with the relative chronologies of the stratigraphies. Part 4 introduces an overall stratigraphy of the site. Part 5 contains the classification and phasing of the excavated objects. Part 6 deals with the Cross-Referencing of the excavated pottery types to the surface ones. Chapter 4 deals with the classification and comparative study of different objects from the site. Chapter 5 deals with the classification of the pottery corpus. Chapter 6 deals with the comparative study of the pottery corpus in two parts. Part 1 introduces the sources of published pottery from Saudi Arabia. Part 2 contains the comparative study on the pottery types established in Chapter 5. Finally, the conclusion is written; followed by the bibliography. 
Holden, T.G. Taphonomic and methodological problems in reconstructing diet from ancient human gut and faecal remains.

The study of ancient human gut and faecal residues can provide some of the most reliable data relating to fast diet. However, as with other forms of archaeological data it suffers from serious taphonomic bias, with some classes of food being well represented and others only poorly. This project attempts to identify more clearly where some of these biases lie, particularly with respect to the matter of differential digestion. In order to achieve this, a series of experiments relating to digestion in modern humans and the survival of different food items through the digestive tract, have been carried out.

The knowledge gained during this study of modern material has then been applied to three separate classes of ancient human gut and faecal remains: a) desiccated human gut contents from a number of locations in South America;

b) waterlogged human gut contents from a number of European bog bodies;

c) discrete, desiccated human palaeofaeces (coprolites) recovered from a midden on the Northern Chilean site of Tulan 54;

The food debris from these samples have been accurately identified and quantified and interpretations made regarding past dietary practices. In the case of the coprolites from Tulan, North Chile, it has also proved possible to compare and contrast the data recovered from coprolite material with both biological material recovered by flotation from the midden itself, and, the gut contents of two well preserved human bodies from an associated cemetery. It has therefore been possible to comment upon the advantages and deficiencies of each class of material which are more usually analysed in isolation.

\section{Al-Mazroo, H. I. A stylistic and comparative study of unpublished pre-Islamic stone sculptures from Arabia}

This thesis has involved the compilation of a catalogue of unpublished pre-Islamic sculptural material, comprising statues, statuettes, reliefs and plaques bearing stylized human faces and inscriptions. The objects come mainly from three known archaeological sites in the kingdom of Saudi Arabia (Qaryat al-Fau, al-'Ula and Fadak), and other unknown sites situated within the South Western region of Arabia (ancient Yemen)

The thesis contains maps, drawings and photographs. The catalogue first divides the objects according to their regions and sites, then sub-divides the objects from South Arabia into groups, types and sub-types. The classification has been done partly on a typological basis, and partly upon a combination of several outstanding aspects, such as method of manufacture and other technical considerations.

A discussion of each individual object or classified object in the catalogue follows its description In these discussions attempts are made to focus on many related aspects such as stylistic and comparative studies, technique and function, and an attempt is also made to assess which tools might have been used in the process of carving.

All the inscriptions published in this thesis were kindly read by Professor A. Al-Ansary and Mr. M. Al-Rousan, and inscription no. 3 in the Appendix was kindly read by Professor A. F. Beeston. 
This study proves that although pre-Islamic Arabia had its own traditions, it was considerably influenced by ancient Near Eastern art, through its religious principles and general characteristics. This study also brings to light new data on pre-Islamic artistic traditions, beliefs, customs and cultural relations between Arabia and neighbouring civilizations.

Reynolds, $P$. Late Roman pottery and settlement in the Vinalopó Valley (Alicante, Spain), A.D. 400-700.

This thesis presents a study of the late Roman archaeology of the Vinalopo Valley, within the regional contexts of south-eastern Spain and the Roman Western Mediterranean.

The road system from the late Republican to Arab period is outlined. Late Roman-Visigothic settlement in the Vinalopo Valley is then assessed. Particular attention is paid to the dating of sites. This is done with pottery from both survey and excavation and with a new typology of late RomanVisigothic period pottery found in the region. Detailed observations on the source and distribution of pottery (local, regional and imported; fine wares, amphorae and coarse wares) in the Vinalopo Valley are made, through time and by class and location of site. Special attention is paid to an analysis of the archaeological evidence for the Byzantine reconquest of south-eastern Spain and its effects on the supply of pottery to the Vinalopo Valley.

The range and relative quantities of imported pottery found in the region are then compared with the distribution of imports on selected Western Mediterranean, in particular, as exporters of foodstuffs and pottery to Western Mediterranean sites through the pre-Vanda., Vandal and Byzantine periods are outlined and discussed. Factors that may have dictated the regional distribution of pottery are suggested. Several major shipping routes and the independent distribution of Eastern Mediterranean and Tunisian goods are also suggested by this archaeological evidence.

It is concluded that the supply of imports to Alicante through the 47th centuries was dictated by changing political trends in "export policy", dependence on imported foodstuffs and pottery to a lesser degree, and the region's location on or by major south-western Mediterranean shipping routes from the East and Tunisia. Contacts with Tunisia are particularly strong and somewhat exceptional from the 5th-mid 6th century. The Byzantine reconquest of south-east Spain maintained the strong links between Carthage and Cartagena, the capital of the Byzantine province, but not Alicante.

Wettasinghe, S. C. A study of the chemical deterioration of paper using Fourier-transform infrared spectroscopy, and the stabilization and strengthening of mechanical wood papers.

The composition and mode of deterioration of a number of old and modern papers of different types were investigated using a variety of techniques including Fourier-transform infrared spectroscopy (FTIR) and differential scanning calorimetry (DSC). Special emphasis was placed on papers based in whole or in part of mechanical wood pulps, as theses are particularly noted for their poor preservation, and have not been so widely studied as the lignin-free papers. FTIR was used to investigate chemical changes occuring in papers as a result of ageing, and to identify paper types 
and additives on a chemical basis by comparison with standards of known origin treated in different ways. DSC was used to look for changes in stability of papers as a result of ageing and following chemical modification.

The causes of paper deterioration have been reviewed and discussed, and the role of acidity and pollutants in paper deterioration further investigated and assessed. Alternative methods of deacidification have been tried, particularly those based on vapour-phase reagents, in an attempt to overcome some of the disadvantages of existing techniques.

Two particular aspects of the conservation of wood-pulp based papers have been investigated. The strengthening of new and already partially deteriorated papers by chemical means has been tried, as has the use of reagents to stabilize the lighin and to limit future deterioration of such papers.

Prospects for the preservation of modern papers of low permanence have been discussed in the light of the work described above.

\section{M.PHIL ABSTRACTS}

Fridriksson, A. Interpretation in Icelandic archaeology. The role of literature and popular antiquarianism

This thesis is a study of the interpretation of archaeological finds in Iceland. After a long tradition of analogies drawn between literary information and archaeological data there has been in recent years a growing concern among archaeologists working in Iceland regarding this method, but its nature and logic has never been examined.

Here, the role of literature and popular antiquarianism is reviewed, in earlier research as well as in contemporary archaeology. Related elements in such methodology include the tales and traditions surrounding ancient monuments and the past. These folkloric explanations of archaeological sites and finds are recorded from the earliest times of written history in Iceland and they are incorporated in present day archaeological study. These traditions are here termed popular antiquarianism, and are distinguished from antiquarianism and archaeology for they do not constitute a learned study or interest, but rather provide a living, improvised explanation of the cultural landscape of the past.

In an attempt to reveal the method of interpretation in Icelandic archaeology a great number of archaeological studies are observed. Ideas and evidence for prehistory, religion, administration and farms are examined, and a number of examples illustrate how support has been sought from the medieval writings.

An analysis of the method, logic and credibility of analogical inferences in Icelandic archaeology reveals the continuity of strong literary impact. Direct references to written sources fade, but the conception of the material culture of the past remains captured in the cosmology of literature and popular antiquarianism. 